\title{
Cidadãos de Segunda Categoria \\ Sofrimento Mental nas Decisões do Superior Tribunal de Justiça Sobre as Medidas de Segurança
}

\author{
Marília De Nardin Budó \\ Professora do departamento de direito da Universidade Federal de Santa Catarina. Doutora em Direito pela UFPR. \\ Mestre em Direito pela UFSC. Graduada em Direito e em Jornalismo pela UFSM. mariliadb@yahoo.com.br

\section{Marina Rocha Bongiorno} \\ Graduada em Direito pela Imed. Pós-Graduada em Direito Penal pelo Damásio Educacional. Advogada. Membro do grupo \\ de pesquisa Poder, Controle e Dano Social do PPGD da Faculdade Meridional. marina.bongiorno@hotmail.com
}

Apesar da adoção pelo Brasil de uma política desinstitucionalizadora sobre as maneiras de lidar com a saúde mental a partir da Lei 10.216/2001, a legislação penal sobre o tema da inimputabilidade do portador de sofrimento mental não foi alterada. Em razão de mudanças gradativas na orientação da jurisprudência brasileira, contudo, alguns avanços ocorreram, como a edição da Súmula 527 do Superior Tribunal de Justiça (STJ). Este artigo tem por objetivo compreender se a construção dessa súmula e sua posterior aplicação por esse Tribunal representaram uma significativa alteração na representação social do portador de sofrimento mental, bem como dos conceitos de periculosidade e das funções da medida de segurança. Para tanto, após a realização de pesquisa exploratória da bibliografia, apresenta-se os resultados de uma pesquisa documental nos acórdãos do STJ sobre medidas de segurança no período de 2014 a 2016. Conclui-se que, apesar de um avanço no que tange à diminuição da média do tempo de cumprimento da medida de segurança, não houve alteração na terminologia utilizada, na compreensão da periculosidade e da finalidade da medida de segurança. A Lei 10.216/2001, apesar de mencionada pontualmente, aparece somente em casos de flagrante ilegalidade na aplicação da lei penal ou de descumprimento da própria orientação do STJ. O chamado inimputável por sofrimento mental continua a ser considerado um cidadão de segunda categoria: por ser visto como um perigo, não goza plenamente nem dos direitos específicos previstos na lei de reforma psiquiátrica, nem das garantias penais.

Palavras-chave: Medidas de segurança. Inimputabilidade. Luta antimanicomial. Periculosidade.

\section{SECOND CATEGORY CITIZENS: MENTAL SUFFERING IN THE SUPERIOR TRIBUNAL} OF JUSTICE DECISIONS ON SAFETY MEASURES

\section{ABSTRACT}

Despite of the adoption by Brazil of a deinstitutionalizing policy on the ways to deal with mental health, from Law $10.216 / 2001$, the criminal law on the theme of the incapacity of the mentally ill person has not changed. However, due to gradual changes in the orientation of Brazilian jurisprudence, some advances have occurred, such as the edition of Supreme Court Summary 527. This article aims to understand if the construction of this summary and its subsequent application by this court represented a significant change in the social representation of the carrier of mental suffering, as well as the concepts of dangerousness and the functions of the security measure. In order to do so, after conducting an exploratory research of the bibliography, the results of a documental research in the STJ's judgments on security measures in the period from 2014 to 2016 are presented. It is concluded that, in spite of a progress with regard to the decrease of the average time of compliance with the safety measure, there was no change in the terminology used, in the understanding of the hazard and the purpose of the safety measure. The Law 10.216/2001, although mentioned sometimes, it appears only in cases of flagrant illegality in the application of criminal law or non-compliance with the STJ's own guidance. The so-called criminal irresponsible continues to be considered a second-class citizen: because it is seen as a danger, it does not fully enjoy either the specific rights provided by the psychiatric reform law or the criminal guarantees.

Keywords: Security measures. Criminal liability. Anti-sylum movement. Dangerousness.

1 Introdução. 2 Culpabilidade e periculosidade: a desumana abordagem penal sobre o sofrimento mental. 30 paradigma antimanicomial após a súmula 527 do STJ. $3.1 \mathrm{~A}$ aferição da periculosidade no discurso do STJ e suas consequências. 3.2 A pena máxima em abstrato como parâmetro: superação ou manutenção do antigo paradigma segregador? 4 Conclusão. 5 Referências. 


\section{INTRODUÇÃO}

A incorporação ao ordenamento jurídico brasileiro dos princípios do Movimento Antimanicomial, por meio da Lei n. 10.216/2001, representa uma das grandes conquistas daquele movimento social. Tendo como espelho e como marco representativo a Lei Italiana 180/1978, conhecida como Lei Basaglia, o Movimento teve início no Brasil entre as décadas de 70 e 80 do século 20. Inicialmente constituído por trabalhadores da área da saúde mental, foi com a adesão de familiares de usuários desses serviços que, mais tarde, o Movimento voltou seu olhar aos usuários dos serviços de saúde mental.

Diante desse histórico, verifica-se uma evolução no que respeita ao enfrentamento das questões relativas às pessoas portadoras de sofrimento mental, suas condições psíquicas, suas necessidades, direitos e diretrizes necessárias em seu benefício. Apesar disso e considerando o contexto histórico de segregação para "purificação" (FOUCAULT, 2005) que permeou por séculos - e ainda deixa vestígios - a questão da loucura, a representação dos "loucos" pela legislação penal brasileira é ainda bastante retrógrada.

Não obstante a concretização das demandas em prol dessa população pela lei de reforma psiquiátrica, não são poucos os autores e operadores do Direito que vêm denunciando a inalteração do tratamento conferido aos inimputáveis ${ }^{1}$ pela legislação penal e pela prática de sua aplicação. Em razão de mudanças gradativas na orientação da jurisprudência brasileira, contudo, alguns avanços ocorreram, como a edição da Súmula 527 do Superior Tribunal de Justiça que prevê o limite de cumprimento da medida de segurança correspondente ao máximo da pena cominada em abstrato ao crime.

Diante dessa tendência, este artigo tem por objetivo compreender se a construção dessa súmula e sua posterior aplicação por esse Tribunal representaram uma significativa alteração na representação social do portador de sofrimento mental, bem como dos conceitos de periculosidade e das funções da medida de segurança. Para o exame dessa questão inicialmente será realizada pesquisa exploratória da bibliografia sobre as normas que se aplicam à pena em comparação àquelas aplicadas à medida de segurança, bem como sobre os limites entre o Direito e a Psiquiatria, entre a culpabilidade e a periculosidade na definição sobre a imputabilidade do agente. Em seguida, apresenta-se os resultados de uma pesquisa documental nos acórdãos do STJ sobre medidas de segurança no período de 2014 a 2016. Nessa pesquisa documental serão abordados dois aspectos em especial: a apropriação do discurso antimanicomial pelo Tribunal e suas as consequências teóricas no que diz respeito à representação social do inimputável, do tratamento conferido à questão da periculosidade e da finalidade das medidas de segurança; e práticas, quanto à aplicação ou não dos princípios da Lei $10.216 / 2001$, por um lado, e penais, de outro.

\footnotetext{
O conceito de inimputabilidade é definido pelo artigo 26 do Código Penal e, segundo esse dispositivo, é isento de pena o agente de crime que, por doença mental ou desenvolvimento mental incompleto ou retardado, não possui capacidade de entender ou de se determinar diante do caráter ilícito da ação ou omissão cometida. Uma vez que os inimputáveis são isentos de pena, a imposição da medida de segurança é vinculada a uma sentença absolutória imprópria e remete à internação em hospital de custódia e tratamento psiquiátrico ou ao tratamento ambulatorial, conforme dispõe o artigo 96 , incisos I e II, do Código Penal.
} 


\section{Democracia}

Humanos e

\section{CULPABILIDADE E PERICULOSIDADE: A DESUMANA ABORDAGEM PENAL SOBRE O SOFRIMENTO MENTAL}

O Código Penal Brasileiro reserva poucos de seus dispositivos para definições a respeito da medida de segurança. Traz, em seu Título VI - Das Medidas de Segurança - quatro artigos que dispõem sobre as espécies de medidas de segurança, da imposição da medida de segurança para o inimputável, do prazo da internação, da perícia médica, da desinternação ou liberação condicional, da substituição da pena por medida de segurança para o semi-imputável, e dos direitos do internado (BRASIL, 2012). Além disso, define o inimputável por "doença mental" no artigo 26. Apesar de a legislação penal ter estruturado vários institutos da pena, que figuram como mecanismos desencarceradores diante da finalidade de reintegração social prevista na Lei de Execução Penal (LEP), como as circunstâncias atenuantes, o regime progressivo, etc., para a medida de segurança restaram poucas previsões.

Conforme explicam Pavarini e Giamberardino (2012, p. 125-126), o Código Penal Brasileiro de 1940 reproduziu os termos adotados pelo legislador italiano em 1930 no que se refere à aproximação entre penas e medidas de segurança, sendo as primeiras cominadas porque "justas" e destinadas ao delinquente responsável, e as segundas, de natureza pessoal, impostas por serem "úteis", conforme finalidades de prevenção especial, tanto de neutralização como de ressocialização dos sujeitos tidos como perigosos.

Com a reforma de 1984, o sistema passou a ser dualista alternativo ou vicariante. Esse sistema caracteriza-se pela alternatividade, e não pela cumulatividade, sendo a pena aplicada aos imputáveis, com fundamento na culpabilidade, e a medida de segurança aplicada aos semi ou inimputáveis, com fundamento na periculosidade, inexistindo, portanto, a possibilidade de serem aplicadas, a um mesmo sujeito, por um mesmo fato, pena e medida de segurança (PAVARINI; GIAMBERARDINO, 2012, p. 125-126).

Na legislação penal, porém, restou ausente a manifestação sobre um ponto crucial dentro da medida de segurança: o limite máximo de seu tempo de duração. O §1ํ do artigo 97 do Código Penal abre espaço para diferentes interpretações ao estabelecer apenas o prazo mínimo para a duração da internação manicomial e consolidar que esta será por tempo indeterminado (BRASIL, 2012).

Sobre a internação por prazo indeterminado, hoje já está consolidado o entendimento, tanto na literatura especializada como nos julgados por todo o país, que ela seria inconstitucional. Como argumenta Nucci (2012, p. 562), a ausência de limite máximo violaria o preceito da vedação de penas de caráter perpétuo. Sendo a medida de segurança uma forma de sanção penal muitas vezes mais grave do que a pena atribuída ao inimputável (QUEIROZ, 2014, p. 523), e cuja finalidade de tratamento se mostrou historicamente falsa, como bem demonstra a criminologia crítica (CARVALHO, 2013, p. 508), deveria o inimputável ser beneficiado por todas as limitações existentes na aplicação tradicional das penas. Segundo Carvalho (2013, p. 515), deveria o juiz realizar a dosimetria da pena, de maneira a limitar a medida ao máximo da pena aplicada em concreto.

A jurisprudência já vem consolidando este entendimento, divergindo, porém, em qual seria o limite. Enquanto inicialmente o STF se pronunciava a respeito definindo os 30 anos, pena máxima prevista no Brasil, hoje já se consolidou no STJ a regra de o limite ser dado pelo 
máximo da pena em abstrato cominada ao ato praticado pelo inimputável (BRASIL, 2015a). Tal interpretação conduziria ao respeito ao princípio da isonomia, de maneira que o inimputável não estivesse sendo punido de maneira mais grave que o imputável.

Outra adversidade encontrada no estudo da legislação penal diz respeito aos critérios para atribuição de culpabilidade ao agente imputável, e de periculosidade àquele inimputável. Como explicita Santos (2008, p. 25), a natureza da atribuição de culpabilidade e de periculosidade aos agentes possuem fundamentos diferentes, de acordo com o discurso oficial da teoria jurídica das medidas de segurança:

O princípio da culpabilidade proíbe punir pessoas inimputáveis porque são incapazes de reconhecer a norma, mas não proíbe a aplicação de medidas de segurança fundadas na periculosidade criminal de autores inimputáveis de fatos puníveis: a relação culpabilidade/pena possui natureza subjetiva, mas a relação periculosidade criminal/medida de segurança possui natureza objetiva de proteção do autor (terapia) e da sociedade (neutralização) [...] (SANTOS, 2008, p. 25).

Essa ponderação reflete a finalidade real da internação manicomial, que é, para além da proteção, tratamento, e recuperação do indivíduo que se encontra sob a tutela do Estado (finalidade declarada da internação), a exclusão seletiva e, consequentemente, estigmatização do sujeito "anormal".

O problema, contudo, desse caráter de livre-arbítrio que fundamentaria a culpabilidade e, portanto, uma imposição de pena ao sujeito, é que ele é indemonstrável, com numerosos autores buscando rechaçá-la para buscar critérios de imputação mais racionais, apropriados e exatos (ROXIN, 2007). Por outro lado, também o determinismo positivista é indemonstrável, e tal dicotomia deve ser superada na busca por outra definição ou a substituição de tal conceito por outro (BUSTOS RAMÍREZ; HORMAZÁBAL MALARÉE, 1999).

Daí a crítica de que o princípio de culpabilidade deve servir como limitação da pena para garantir a liberdade do cidadão contra o poder do Estado, ao contrário de fundamentar a pena e legitimar o poder do Estado contra o indivíduo (SANTOS, 2008). Nesse sentido, "a culpabilidade nunca exige uma pena; somente sua ausência exclui a pena e sua magnitude determina a fronteira máxima da pena" (SANTOS, 2008, p. 288). Busca-se, com isso, fugir da culpabilidade pela conduta de vida, enfocando-a na "[...] capacidade de motivação do agente para o fato por ele realizado, em face dos apelos normativos da ordem jurídica aos quais tivera acesso" (TAVARES, 2011, p. 127). ${ }^{2}$ Além disso, tal perspectiva conduz o juízo de culpabilidade a uma vinculação às funções declaradas da pena, defendida, por exemplo, por Roxin (2007): daí a sua associação com a determinação da responsabilidade com base na necessidade da pena. ${ }^{3}$

\footnotetext{
Desse ponto decorrem as causas supralegais de exclusão da culpabilidade de que trata Santos (2008): o fato de consciência, a desobediência civil, o conflito de deveres etc. Também entra aí a questão dos limites do erro de proibição que, segundo o autor, "[...] em sociedades com elevadas taxas de exclusão do mercado de trabalho e do sistema escolar - ou seja, marcadas pela pobreza e pela ignorância, como é o caso da sociedade brasileira -, a frequência do erro de proibição e a imprecisão dos critérios de evitabilidade/inevitabilidade respectiva reclama atitudes democráticas na sua avaliação: bitola larga para a inevitabilidade, bitola estreita para a evitabilidade do erro de proibição". Ainda, a abordagem de Zaffaroni e Pierangeli (2008) a respeito da ampliação dos limites do erro de proibição em razão da não introjeção da norma, o que, em sociedades multiculturais é uma realidade que não pode deixar de ser tida em consideração pelo jurista.

3 Para Bustos Ramírez e Hormazábal Malarée (1999, p. 329), a percepção de Roxin de que a culpabilidade deve ser fundada na finalidade da pena é um evidente salto lógico, pois "[...] os fins da pena não podem substituir seus pressupostos".
} 


\section{Democracia}

Humanos e

Em seu conceito normativo, é amplamente aceita na doutrina brasileira a definição de culpabilidade como reprovabilidade, construída por Frank (2002) em 1907. O juízo de reprovação é possibilitado mediante a análise de três categorias: a imputabilidade, entendida como "condições pessoais mínimas que capacitam o sujeito a saber o que faz"; a consciência da antijuridicidade, "como conhecimento concreto do valor que permite ao autor imputável saber, realmente, o que faz", e a exigibilidade de conduta diversa, "como expressão de normalidade das circunstâncias de fato e indicação de que o autor tinha o poder de não fazer o que fez" ${ }^{4}$ (SANTOS, 2008, p. 281-282).

Apesar de essa ideia de culpabilidade como reprovabilidade, teorizada há mais de cem anos, ser aceita pela maior parte dos juristas brasileiros, tal definição é duramente posta em xeque por Batista (2011). Para o autor, a reprovação somente é possível se baseada em um juízo moral, que torna necessária a adoção de uma determinada ordem de valores como sendo superior às demais. No Estado de Direito, contudo, em que a Constituição incorpora o princípio da autonomia moral da pessoa, o juiz não tem o direito de censurar ou repreender o condenado, o que seria uma concessão a preconceitos morais e religiosos inadmissíveis no Direito Penal (BATISTA, 2011). Trata-se de uma execração moral dos condenados, perpetrada por juízes e outros agentes do sistema penal, além da própria mídia. Em sua opinião, "talvez tenhamos que renunciar, definitivamente, ao conceito de culpabilidade, tão central na civilização judaico-cristã ocidental para tentar salvar, de toda contaminação moral [...] o conceito moderno de responsabilidade" (2011, p. 178).

A superação do conceito de culpabilidade também é proposta por Bustos Ramírez e Hormazábal Malarée (1999, p. 340), para quem não se pode julgar os sujeitos de forma valorativa, que leve em consideração valores absolutos ou de verdade absoluta, o que vai de encontro aos princípios de uma sociedade pluralista e democrática. "Culpabilidade é responsabilidade, não é uma reprovação, nem a abordagem de que se podia agir de outra maneira; tampouco se trata de chegar à conclusão de que é um ser determinado e, portanto, sem consciência, um animal, um simples processo natural". ${ }^{5}$ Diante dessa definição de culpabilidade, Bustos Ramírez e Hormazábal Malarée (1999, p. 336) irão concordar que a responsabilidade do sujeito implica três condições: a imputabilidade, ou exigibilidade sistêmica, a exigibilidade da consciência do injusto e a exigibilidade da conduta. Assim, a inimputabilidade implica inexigibilidade ao autor por parte do sistema (p. 342).

\footnotetext{
Para uma análise de diferentes definições materiais do conceito normativo de culpabilidade, cf. Santos (2008, p. 287294). Destaca-se a percepção de Santos, para quem a culpabilidade está assentada na alteridade, e não na presunção de liberdade. Pelo fato de viver em sociedade, o homem é responsável por suas ações perante o outro. Para uma leitura diferenciada a respeito da culpabilidade, com base, sobretudo, em Foucault e Freud, cf. Santos (2008).

5 Tradução livre do original em espanhol: "Culpabilidad es responsabilidad, no es un reproche, ni el planteamiento de que se podía actuar de otra manera; tampoco se trata de llegar a la conclusión de que es un ser determinado y, por tanto, sin conciencia, un animal, un simple proceso natural. Responsabilidad implica que el hombre es actor, esto es, que desempeña un papel y, por tanto, alcanza conciencia de él; pero como actor está dentro de un drama, de una relación social, y su conciencia está determinada por ella específicamente y por los controles sociales ejercidos sobre ella" (BUSTOS RAMÍREZ; HORMAZÁBAL MALARÉE, 1999, p. 333). Ainda, na continuação da definição de responsabilidade, Bustos a identifica com a exigibilidade por parte do Estado: "El término responsabilidad se aviene más con el principio de la autonomía ética de la persona. Toda persona por el sólo hecho de serlo es autónoma y responsable de sus respuestas dentro del sistema. El problema es en qué medida el Estado puede exigirle una determinada respuesta a una persona determinada en una situación concreta. En definitiva, mejor que culpabilidad, responsabilidad es igual a exigibilidad. La responsabilidad del sujeto implica tres condiciones: la exigibilidad sistémica o imputabilidad; la exigibilidad de la conciencia del injusto; la exigibilidad de la conducta" (BUSTOS RAMÍREZ; HORMAZÁBAL MALARÉE, 1999, p. 336).
} 
A categoria dos inimputáveis surge como forma de limitar a punição estatal àqueles que tiveram condições de, na prática de sua conduta, entender o caráter ilícito do fato e se autodeterminar de acordo com esse entendimento. Por isso, no artigo 26 do Código Penal, os doentes mentais são considerados inimputáveis e, portanto, irresponsáveis penalmente, pois "para que se possa reprovar uma conduta a seu autor, é necessário que ele tenha agido com um certo grau de capacidade, que lhe haja permitido dispor de um âmbito de autodeterminação" (ZAFFARONI; PIERANGELI, 2008, p. 535, grifos no original). ${ }^{6}$

Como notam Bustos Ramírez e Hormazábal Malarée (1999, p. 362, tradução livre), “a declaração de inimputabilidade implica em estabelecer maiores garantias ao sujeito, não diminuí-las". Na prática, porém, os direitos e garantias passam a ser deixados de lado na medida em que o acusado é declarado inimputável. Essa dificuldade em compatibilizar garantias e direito penal de autor reflete o seu caráter intrinsecamente autoritário: "O fundamento do castigo no direito penal de autor é o próprio autor e as valorações abstratas que se possa fazer sobre esse autor. Assim, será castigado porque é perigoso, ou é traidor, ou imoral, de uma etnia diferente, etc." (BUSTOS RAMÍREZ; HORMAZÁBAL MALARÉE, 1999, p. 312, tradução livre).

E é nesse direito penal de autor que reside a medida de segurança por tempo indeterminado. Para Pavarini e Giamberardino (2012, p. 144), "O pressuposto da periculosidade social ou criminal é de natureza subjetiva, como é evidente, sempre vinculado a prognósticos sobre o comportamento do indivíduo. Tratar-se-á sempre de uma presunção, que historicamente e atualmente se manifesta nas formas legal ou judicial". Por ter caráter subjetivo, associado ao comportamento humano, há autores e autoras que não reconhecem o conceito de periculosidade como elemento essencial para se determinar ou não a internação, sobretudo baseados em seu caráter preditivo do futuro a partir do conhecimento da personalidade de um autor no passado. É o que defendem Pavarini e Giamberardino (2012, p. 145): "a denominada 'prognose criminal' nada tem de científica, mas se rege unicamente pela capacidade intuitiva do juiz, carregando toda a arbitrariedade que isso pode determinar (e objetivamente determina)".

Em virtude da atribuição de periculosidade ao agente inimputável, este depende de perícias médicas durante o período de internação para que se ateste a cessação dessa condição e se torne possível sua saída do hospital de custódia. Nessa fase de institucionalização entram em cena os saberes técnicos, que têm o poder de decidir sobre a cessação ou não da medida. Ao juiz fica reservada a atribuição de extrair as consequências jurídicas dos laudos psiquiátricos, definindo a libertação ou a manutenção da privação da liberdade. Como observa Foucault, isso faz com que a sentença que parte dessas perícias "[...] implique mais ou menos obscuramente em juízos de normalidade, atribuições de causalidade, apreciações de eventuais mudanças, previsões sobre o futuro dos delinquentes" (FOUCAULT, 2009).

\footnotetext{
Para Zaffaroni et al. (2010, p. 65), a culpabilidade de ato, medida pelos critérios da imputabilidade, potencial consciência da antijuridicidade e exigibilidade de conduta diversa tem a função de apresentar o limite do poder punitivo. Após essa análise, porém, é necessário identificar um outro dado a determinar a culpabilidade: a vulnerabilidade. Nessa perspectiva, dada a arbitrária seletividade criminalizante, que "privilegia" alguns com a sanção criminal mais do que outros, é necessário observar que dadas as características do autor, o esforço que ele realizará para ser controlado pelo sistema será menor ou maior conforme o seu afastamento ou proximidade ao poder. Assim sendo, quanto mais vulnerável é o autor de uma conduta, menor é a sua culpabilidade, dado que menor esforço precisa ser feito para que seja surpreendido pelo sistema de controle penal.
} 


\section{Democracia}

Humanos e

Declarar a periculosidade de uma pessoa possui, então, um caráter constitutivo que determinará dali em diante tudo o que se saberá e decidirá sobre ela dali em diante. A noção de "sujeito perigoso" é o resultado de uma evolução da inserção da Psiquiatria no Direito, que, no estudo de Foucault (2004), se inicia no século 19 com a patologização do crime, especialmente a partir da criação da "monomania homicida".' A partir desse momento, a Psiquiatria ganha espaço, atribuindo ao tratamento da loucura um caráter de defesa social, e a própria pena vai assumir esse caráter de ingerência estatal no indivíduo em razão do risco potencial de voltar a praticar crimes. A principal consequência da inserção do periculosismo no Direito Penal é a transformação da ideia de responsabilidade, por um lado, e a mudança no sistema de Justiça, que "tende a se exercer sobre aquilo que se é" (FOUCAULT, 2004, p. 24).

No entendimento de Foucault, a "norma", entendida como regra de conduta, como lei informal, como princípio de conformidade; a norma a que se opõe à irregularidade, à desordem, à esquisitice, à excentricidade, ao desnivelamento, à discrepância, é introduzida pela Psiquiatria no campo sintomatológico, em fins do século 19 e início do século 20. Daí que a Psiquiatria será essencialmente a ciência e a técnica dos anormais, dos indivíduos anormais e das condutas anormais. "O que acarreta evidentemente, como primeira consequência, que o encontro crime-loucura não será mais, para a psiquiatria, um caso-limite, mas o caso regular" (FOUCAULT, 2010, p. 139).

Um ponto interessante dessa análise de Foucault é aquele que mostra a inversão violenta das consequências jurídicas do crime na medida em que se aproximam o criminoso e o anormal: se a sanção imposta ao criminoso, desde uma perspectiva clássica, é limitada à sua responsabilidade pelos danos causados, ou seja, vinculada ao fato, a sanção imposta ao anormal é ilimitada, pois diz com a sua biografia, e é vinculada ao autor. Trata-se, assim, da transformação da maneira como a loucura evoluiu na prática penal (FOUCAULT, 2009). O autor demonstra que o Código Penal francês de 1810 - e podemos afirmar o mesmo dos códigos de $1830^{8}$ e de $1890^{9}$ no Brasil - previa que não haveria crime se o autor estivesse em estado de demência no instante do ato. Assim, a culpa jamais poderia ser atribuída ao louco, e tampouco uma sanção. Não foi esse, porém, o caminho seguido pelo Direito: "em vez de a loucura apagar o crime, no sentido primitivo do artigo 64, qualquer crime agora e, em última análise, qualquer infração, incluem como uma suspeita legítima, mas também como um direito que

\footnotetext{
A Psiquiatria teve o papel de formular a existência do instinto criminal dos criminosos, chegando a forjá-la como categoria nosográfica - a monomania homicida, por exemplo - de modo a legitimar cientificamente a relação entre crime, anormalidade e perigo, sobretudo nos casos dos chamados "monstros", que praticam os crimes sem razão. "Em suma, foi preciso que a Psiquiatria, para funcionar como eu lhes dizia [como ramo da higiene pública], estabelecesse a pertinência essencial e fundamental da loucura ao crime e do crime à loucura" (FOUCAULT, 2010, p. 102).

8 "Art. 27. Não são criminosos: [...] § 3으 Os que por imbecilidade nativa, ou enfraquecimento senil, forem absolutamente incapazes de imputação; $\S 4$ ㅇ Os que se acharem em estado de completa privação de sentidos e de intelligencia no acto de commetter o crime; Art. 29. Os individuos isentos de culpabilidade em resultado de affecção mental serão entregues a suas familias, ou recolhidos a hospitaes de alienados, si o seu estado mental assim exigir para segurança do publico" (BRASIL, 1890).

9 “Art. 10. Tambem não se julgarão criminosos: [...] 2응 Os loucos de todo o genero, salvo se tiverem lucidos intervallos, e nelles commetterem o crime. [...]. Art. 12. Os loucos que tiverem commettido crimes, serão recolhidos ás casas para elles destinadas, ou entregues ás suas familias, como ao Juiz parecer mais conveniente" (BRASIL, 1830).
} 
podem reivindicar, a hipótese da loucura ou em todo caso da anomalia" (FOUCAULT, 2009, p. 24). E ao se detectar a loucura, a sanção imposta - pelo menos no caso brasileiro - vem a ser mais gravosa do que quando ela não é detectada.

Birman (2011, p. 87) explica que a união entre os saberes jurídico e psiquiátrico resultou no deslocamento da problemática penal do registro do crime para o registro do criminoso. Com isso, a questão da responsabilidade foi colocada em primeiro plano. O autor resume, acerca dessa constatação, que

(...) o que passou a estar em pauta na cena criminal foi o fato de que o sujeito poderia ser considerado responsável mesmo que não tivesse cometido qualquer falta, em decorrência do risco e do perigo que passaria a implicar para a ordem social. $\mathrm{O}$ que passou a ser avaliado na cena criminal é quem o sujeito é, para o julgamento efetivo de seu delito. Pela mediação disso que o risco e a periculosidade sociais seriam avaliados na cena criminal, sempre em nome da defesa social. Enfim, as teses da antropologia criminal e da defesa social se impuseram no campo do direito penal.

Verifica-se, portanto, que os critérios de culpabilidade e periculosidade encontram-se em crise, vez que mesmo o primeiro, utilizado nos casos penais que envolvem imputáveis, é produzido com base em elementos instáveis, podendo, inclusive, carregar preconceitos, estereótipos e juízos negativos pré-constituídos.

Ao serem depositados em manicômios, os inimputáveis são abandonados à própria sorte, não se atribuindo a eles diversos institutos cabíveis à pena e, portanto, ao condenado culpável. Carvalho e Weigert (2013, p. 74-75) interpretam que:

No âmbito do direito penal material, o status da inimputabilidade obstaculiza a incidência de uma série de causas de exclusão da tipicidade (princípio da insignificância e princípio da adequação social), da ilicitude (consentimento do ofendido), da própria culpabilidade (coação moral irresistível, erro de proibição inevitável, inexigibilidade de conduta diversa) e da punibilidade (prescrição). Na órbita processual são afastados inúmeros institutos despenalizadores (composição civil, transação penal, suspensão condicional do processo). Na esfera da execução da medida de segurança são excluídos inúmeros direitos assegurados aos presos (remição, detração, progressão de regime, livramento condicional).

Ainda, no que respeita à anteriormente mencionada privação (ao inimputável) de direitos previstos para os presos, Carvalho e Weigert (2013, p. 75) asseveram que se a condição de inimputabilidade gera um status jurídico privilegiado, não se justifica que ao inimputável não sejam assegurados todos os direitos materiais e as garantias processuais que são asseguradas ao réu ou ao condenado imputável. Da distinção teórica entre culpabilidade e periculosidade - provenientes de duas tradições criminológicas que se distanciam para se encontrarem (BARATTA, 2002) - nascem as iniquidades referidas anteriormente.

O reconhecimento de que alguém é portador de sofrimento psíquico, porém, ao invés de retirar direitos, deveria ter como consequência a sua ampliação. A Lei n.o 10.216/2001 vem justamente fazer isso: elencar os direitos da pessoa portadora de transtorno mental (ar- 


\section{Democracia}

Humanos e

tigo $2 \stackrel{2}{ }$, § único), ${ }^{10}$ responsabilizar o Estado no que se refere à assistência aos pacientes internados (artigo 3ㅇ), direcionar as diferentes modalidades de internação, sempre como ultima ratio (artigo 4ㅇ).

A Lei visa, em linhas gerais, à adoção de medidas que garantam os direitos do paciente em tratamento e que esse tratamento não seja apenas médico, mas sim que compreenda a assistência social, serviços psicológicos, ocupacionais, de lazer, entre outros (BRASIL, 2001, ar-

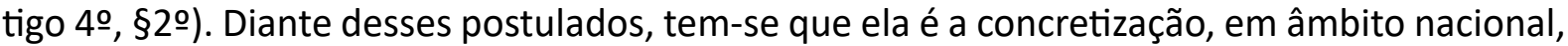
das demandas do movimento antimanicomial e, por esse motivo, é tão relevante na área da saúde mental.

Queiroz (2014, p. 527-528) destaca que a referida lei é plenamente aplicável às medidas de segurança, tipo de internação denominada "internação compulsória", o que deve levar necessariamente a uma releitura da legislação penal, sendo a principal modificação a sua finalidade preventiva especial. A internação não propicia por si só a reinserção social, o objetivo da intervenção estatal deve ser o de tê-la como finalidade permanente do tratamento do paciente em seu meio (artigo 4으, $§ 1$ 으). Assim sendo, toda e qualquer disposição que tiver subjacente a ideia de castigo será revogada.

O sistema denominado "open door", defendido por este paradigma, implica necessariamente a passagem do portador de sofrimento mental da condição de objeto de intervenção estatal para a de sujeito ativo nas definições sobre seu futuro. A representação social do inimputável por sofrimento psíquico não é o do completamente alienado, é o que pretende garantir a sua responsabilização por seus atos passados (crime), por seu tratamento e, inclusive, pelo seu futuro (CARVALHO; WEIGERT, 2013).

Assim, a internação deve ter caráter excepcional também em caso de medida de segurança, considerando que a lei abarca esse tipo de internação. Nesse sentido, a lei prioriza o emprego de recursos extra-hospitalares, conforme se conclui da leitura do artigo 40: "A internação, em qualquer de suas modalidades, só será indicada quando os recursos extra-hospitalares se mostrarem insuficientes" (BRASIL, 2001).

Mesmo com a consolidação dos postulados defendidos pelo Movimento Antimanicomial por meio da legislação supramencionada, essa pretensão do movimento de transformar condições e representações acerca da loucura com o fim de atingir uma sociedade sem manicômios encontra diversos entraves em seu percurso. Um dos pontos de partida para a modificação de percepções acerca da loucura e do "louco" encontra-se na reforma da linguagem, no que se refere às maneiras de abordagem ao sujeito portador de distúrbio psíquico. A nomenclatura habitualmente utilizada para se referir a esse sujeito - "louco", "doente mental" - carrega uma carga de crítica, classificação e, logo, de estigmatização, e a importância do enfrentamento a essa linguagem é visualizada a partir dessa percepção.

\footnotetext{
10 São direitos da pessoa portadora de transtorno mental: I - ter acesso ao melhor tratamento do sistema de saúde, consentâneo às suas necessidades; II - ser tratada com humanidade e respeito e no interesse exclusivo de beneficiar sua saúde, visando alcançar sua recuperação pela inserção na família, no trabalho e na comunidade; III - ser protegida contra qualquer forma de abuso e exploração; IV - ter garantia de sigilo nas informações prestadas; V - ter direito à presença médica, em qualquer tempo, para esclarecer a necessidade ou não de sua hospitalização involuntária; VI - ter livre acesso aos meios de comunicação disponíveis; VII - receber o maior número de informações a respeito de sua doença e de seu tratamento; VIII - ser tratada em ambiente terapêutico pelos meios menos invasivos possíveis; IX - ser tratada, preferencialmente, em serviços comunitários de saúde mental.
} 


\section{PARADIGMA ANTIMANICOMIAL APÓS A SÚMULA 527 DO STJ}

O juízo de periculosidade e as consequências da rotulação de pessoas como perigosas têm como consequência, na prática, a sua destituição da posição de sujeito de direitos, alçando-as àquela de risco à sociedade. No embate entre os discursos de defesa da sociedade com os de crítica antimanicomial da medida de segurança, várias inconsistências jurídicas acabam aparecendo.

Se a definição acerca da manutenção ou revogação da medida de internação manicomial depende do saber médico, de que forma o juiz, no caso concreto, se apropria do discurso médico? Qual é a forma de aplicação, pelo juiz, das avaliações psiquiátricas do inimputável mental? Por outro lado, qual é a o preparo que tem hoje o Judiciário para lidar com os avanços no campo psiquiátrico, sobretudo em relação à utilização da privação da liberdade como ultima ratio?

Apesar de vários terem sido os autores a apontarem o despreparo do Judiciário no que tange à mudança de paradigma trazida pela luta antimanicomial, ocorreu uma mudança gradativa na jurisprudência do STJ, aparentemente reconhecendo os erros de segregação perpétua do passado. Essa mudança foi contemplada na Súmula 527, que define como prazo limite da medida de segurança aquele estabelecido como máximo da pena em abstrato cominado ao delito. Questiona-se, então: A construção e posterior aplicação da Súmula 527 do STJ representaram uma significativa alteração na representação social do portador de sofrimento mental, bem como dos conceitos de periculosidade e das funções da medida de segurança?

Para responder ao questionamento, a seguir apresenta-se os resultados de uma pesquisa documental em toda a jurisprudência do STJ, nos anos 2014, 2015 e 2016. Para a obtenção dos julgados foi utilizada como termo de pesquisa no site do Superior Tribunal de Justiça a expressão "medida de segurança". Com essa amplitude de busca foi possível atingir as representações sobre a medida de segurança e a periculosidade que culminaram com a limitação, pelo STJ, do prazo máximo da medida de internação ao máximo da pena em abstrato do crime pelo qual o inimputável foi julgado. ${ }^{11}$ Foram 80 os julgados encontrados, os quais foram classificados e alguns selecionados para a pesquisa qualitativa.

Conforme será abordado, o entendimento sumulado já era aplicado no período anterior à publicação da Súmula pelo STJ, que seguiu os parâmetros dispostos pelo Supremo Tribunal Federal nesse sentido. Esse entendimento é, em tese, mais benéfico àqueles que são submetidos ao cumprimento de medida de segurança, pois com a imposição de limites para a duração dessa espécie de sanção penal tem-se respaldo jurídico para não permitir que a medida tenha caráter perpétuo. Além disso, essa Súmula traz a possibilidade de redução da média de tempo de institucionalização, visto que antes aplicava-se, por analogia, o artigo 75 do Código Penal, que impunha o prazo máximo de 30 anos, independentemente do crime pelo qual o internado havia sido julgado.

\footnotetext{
${ }^{11}$ A Súmula 527, publicada em maio de 2015, estabelece que o limite máximo para cumprimento da medida de segurança será o máximo de tempo cominado ao crime em abstrato. Eis os termos da referida Súmula, que consolida o entendimento do STJ sobre a medida de segurança: "O tempo de duração da medida de segurança não deve ultrapassar o limite máximo da pena abstratamente cominada ao delito praticado" (BRASIL, 2015a).
} 


\section{Democracia}

Humanos e

\subsection{A aferição da periculosidade no discurso do STJ e suas consequências}

Neste item apresenta-se a construção da noção de periculosidade pelo STJ a partir da finalidade da medida de segurança e sua distinção em relação à pena.

a) Medida de segurança não se confunde com pena: a finalidade

São numerosos os julgados de habeas corpus nos quais o paciente, declarado inimputável e absolvido impropriamente, está internado em presídio comum por ausência de vagas em hospital de custódia. Nos 20 casos encontrados, o STJ foi unânime em contrariar as decisões dos Tribunais estaduais ${ }^{12}$ para conceder a ordem de habeas corpus e determinar a imediata transferência do internado a hospital de custódia, ou, em caso de ausência de vagas, a tratamento ambulatorial. Isso porque "[...] a manutenção de estabelecimentos adequados ao cumprimento da medida de segurança de internação é de responsabilidade do Estado, não podendo o paciente ser penalizado pela insuficiência de vagas" (BRASIL, 2014a). Dessa forma, o STJ se posiciona-se pacificamente "no sentido de ser inadmissível a segregação em penitenciária, de inimputável submetido à medida de segurança de internação enquanto aguarda o surgimento de vaga em hospital de custódia" (BRASIL, 2014b). O entendimento passa a ser então o de que em caso de inexistência de vagas, deve haver a substituição da medida aplicada por tratamento ambulatorial (BRASIL, 2014c).

Dessas decisões, contudo, o interessante para esta pesquisa é a definição que faz o STJ a respeito da medida de segurança e sua diferenciação em relação ao que é a pena. Isso levou à criação da categoria a seguir:

\section{a.1) Finalidade da medida de segurança: tratamento e cura}

Em todas as 20 decisões sobre a inadmissibilidade de inimputáveis permanecerem em prisões comuns enquanto aguardam vagas em hospitais de custódia, uma frase sobressai: " $A$ medida de segurança não se confunde, em absoluto, com a pena" (BRASIL, 2014d). Enquanto várias delas apenas anunciam os precedentes, outros se detêm mais no esclarecimento dessa distinção. No voto anteriormente citado, a principal distinção é dada pela finalidade: "oportuno relembrar a finalidade da medida de segurança, destinada ao tratamento e cura daquele que praticou um fato típico e ilícito" (BRASIL, 2014d). O pressuposto da cura é a doença, no caso, o sofrimento psíquico que, traduzido pela periculosidade, chama a necessidade da intervenção estatal. Para tanto é necessário um estabelecimento adequado: "tanto o Código Penal como a Lei de Execução Penal garantem que, ao sentenciado inimputável, será aplicada medida curativa, a ser cumprida em instituição apropriada" (BRASIL, 2014d). Daí o entendimento de que, sem tratamento - o que ocorre nas prisões comuns - a medida não cumpre com a finalidade, havendo "flagrante ilegalidade".

Além da finalidade de cura, da necessidade de tratamento e de um estabelecimento adequado, esse voto, tomado como exemplificativo, ainda traz uma referência fundamental: a manutenção do paciente em prisão comum indica a existência de um constrangimento ilegal, reconhecendo a violação de seus direitos específicos, previstos na lei da reforma psiquiátrica (Lei n. 10.216/2001). O voto ainda transcreve a íntegra do artigo 20 da referida Lei. 0

12 São Paulo (16), Rio Grande do Sul (1), Tocantins (1), Minas Gerais (1), Distrito Federal (1). 
reconhecimento da aplicabilidade dessa lei às pessoas submetidas à medida de segurança é rara, conforme se verá a seguir, e mostra um avanço na jurisprudência do Tribunal. Em outra decisão, além da referência à Lei e à necessidade de sua aplicação na medida de segurança, o relator ainda afirma que:

Na mesma esteira, ao dispor acerca das diretrizes em atenção aos pacientes judiciários e à execução da medida de segurança, a Recomendação n. 35/2011-CNJ adota clara preferência "à política antimanicomial, sempre que possível, em meio aberto" (item I), com a ressalva de que em caso de internação, "ela deve ocorrer na rede de saúde pública ou conveniada, com acompanhamento do programa especializado de atenção ao paciente judiciário, com observância das orientações previstas nesta recomendação" (item III) (BRASIL, 2014e).

No caso julgado antes exposto, o Tribunal de Justiça de São Paulo havia decidido pela manutenção da prisão do paciente, que já se encontrava nessa condição há mais de três anos sem qualquer tipo de tratamento (BRASIL, 2014e). Nesse julgamento, o Tribunal de Origem entendeu que, apesar da situação irregular em que se encontrava o paciente, sua imediata colocação em liberdade traria sérios riscos ao meio social, diante do grau de sua periculosidade. Assim, o Tribunal invocou o princípio do in dubio pro societate, fazendo esse prevalecer em detrimento aos direitos da pessoa portadora de transtorno mental. A ilegalidade dessa decisão foi apontada pelo Relator do STJ, sem qualquer menção à periculosidade do paciente ou mesmo a laudos periciais (BRASIL, 2014e).

Em nenhum momento, porém, é colocada em questão a própria definição da doença mental, do tratamento e da cura de que fala o magistrado. A reinserção social, que é a finalidade de qualquer internação psiquiátrica após a reforma simplesmente não aparece no discurso do ministro que, pelo menos, citou a referida lei (QUEIROZ, 2014).

Em outro caso, agora relacionado à possibilidade de aplicação de tratamento ambulatorial ao internado por fato previsto com pena de reclusão no Código Penal, contrariando o artigo 97 do mesmo Código, o ministro também refere-se à reforma psiquiátrica e à liberdade de ir e vir como regra: "[...] não se pode ignorar que, há tempos, iniciativas como o "Luta Antimanicomial" - inspiradora, no Brasil, da Lei Paulo Delgado, Lei n. 12.016/2001 - buscam a reforma do atual cenário psiquiátrico e que a realidade brasileira reclama outras alternativas de melhor e mais eficaz recuperação do enfermo". Esse entendimento, também minoritário, mesmo dentro do STJ, está em consonância com toda a tendência mundial de desmanicomialização, e na contramão das políticas brasileiras ligadas à medida de segurança. Novamente, porém, apesar de referir a Lei, não cita sua principal consequência: a necessidade de reinserção social depende da desinstitucionalização, em primeiro lugar.

Nota-se, então, que a representação social da pessoa com sofrimento mental segue sendo aquela do inimputável, o lugar do irresponsável, objeto de intervenção estatal. Além disso a invocação da reforma psiquiátrica somente ocorreu em casos em que: a) houve a prisão em presídio comum; b) as condutas eram insignificantes; c) não há laudos psiquiátricos afirmando a periculosidade; d) ou houve excesso de prazo em relação à pena e abstrato cominada ao delito. A seguir, verifica-se em que casos a periculosidade é avaliada na relação com a finalidade de defesa da sociedade, de modo a comparar as duas categorias. 


\section{Democracia}

Humanos e

\section{a.2) Finalidade da medida de segurança: defesa da sociedade diante da periculosidade do agente}

Apesar de o entendimento do STJ ser pacífico em relação à inadmissibilidade da prisão do inimputável em presídio comum pela falta de vagas em estabelecimento adequado, a justificativa quanto à finalidade da medida de segurança diverge. Em outra decisão sobre a mesma temática, o ministro relator concorda nos argumentos com a decisão a quo do Tribunal de Justiça de São Paulo, para: definir a periculosidade a partir da gravidade dos fatos atribuídos ao paciente; afastar a aplicação da Lei 10.216/2001; definir a finalidade da medida como proteção da sociedade (BRASIL, 2014f):

Conforme bem salientado pelo Ministério Público, em que pese a Lei $n^{\circ}$. 10.216/2001 ser destinada àqueles que sofrem perturbações de ordem mental de um modo geral, é omissa acerca daqueles que praticaram crimes graves em virtude desses transtornos e foram submetidos à medida de segurança. Ademais, o reeducando foi sentenciado por crime sexual, lesão corporal e resistência, não podendo, desta forma, permanecer em um leito comum de hospital geral sem qualquer contenção, pondo em risco outros pacientes do local. Assim, conclui-se que as disposições contidas na Lei 10.216/2001 são incompatíveis com o instituto da medida de segurança (...) (BRASIL, 2014f).

Destaca que a periculosidade do agente estava demonstrada em virtude da prática de diversos delitos, incluindo furto qualificado, estupro e incêndio, concluindo-se que, por isso, a concessão da liberdade pleiteada seria temerária (BRASIL, 2014f). No conflito entre o interesse público, privilegiado no juízo a quo, e os direitos da pessoa com sofrimento mental, o relator pondera

(...) Consubstanciada a necessidade de custódia do paciente a bem da ordem pública, evidenciada pela sua periculosidade, não é razoável reconhecer o pleito formulado, colocando o paciente em liberdade até o surgimento de vaga em estabelecimento adequado. Entretanto, não se pode negar que a sua permanência em presídio é medida que afronta os princípios constitucionais relacionados à dignidade da pessoa humana e à legalidade, razão pela qual concedo a ordem, de ofício, para determinar a imediata transferência do paciente para Hospital de Custódia e Tratamento Psiquiátrico ou outro estabelecimento adequado, e, na falta de vaga, observando as cautelas devidas, considere o Juízo das Execuções a possibilidade de substituição da internação por tratamento ambulatorial, até que surja vaga em estabelecimento adequado à sua condição (...) (BRASIL, 2014f).

Esse último caso evidencia a definição, pelo STJ, da periculosidade baseada exclusivamente na gravidade dos delitos praticados, os quais indicariam uma prognose negativa, sem menção a qualquer laudo pericial. Apesar do acolhimento do discurso referente à periculosidade e à defesa da sociedade, mesmo que em decorrência da gravidade do delito, o STJ não permitiu que o paciente permanecesse em estabelecimento prisional comum.

Em poucos casos há análise de laudos psiquiátricos, de modo que a questão da periculosidade aparece de maneira secundária, porém nos casos em que ela aparece percebe-se a preponderância da atribuição da periculosidade em razão: a) dos antecedentes criminais; b) da gravidade do fato; $\mathrm{c}$ ) de laudos psiquiátricos o atestando.

Em alguns deles há o conflito entre dois ou mais desses critérios. No caso do HC 230.842 -SP, o laudo psiquiátrico indica a necessidade de tratamento ambulatorial com medicamentos pelo período de dois anos. Não obstante o laudo, o tribunal a quo decidiu pela internação em ra- 
zão de o crime ser tráfico de drogas, punido com reclusão. Por outro lado, o STJ concedeu a ordem de habeas corpus, determinando o tratamento ambulatorial, e seguindo, portanto, a orientação psiquiátrica.

Em outro caso, o do HC 214.143, não há laudo indicando a periculosidade do agente, sequer o possível tratamento. Com base nos antecedentes criminais e na pena de reclusão do crime de furto, no entanto, o Tribunal de origem havia determinado a medida de internação. O STJ decide, então, encaminhá-lo ao tratamento ambulatorial, reconhecendo não haver prova da necessidade da privação da liberdade, a qual deve ser exceção, e não regra.

No HC 217.892 - SP está presente nos autos o laudo psiquiátrico demonstrando a cessação da periculosidade, e a recomendação médica de continuidade do tratamento. Nesse caso, o juízo da execução seguiu a orientação do laudo, declarando extinta a punibilidade e indicando tratamento em hospital psiquiátrico. O Tribunal a quo, porém, determinou que permanecesse a medida de segurança, agora na modalidade de tratamento ambulatorial. O STJ decidiu que não havia constrangimento ilegal na não declaração da extinção da punibilidade. Assim, o acolhimento ou não do laudo em muitos casos se dá de maneira equívoca, fazendo com que o laudo negativo sempre cumpra o efeito de prejudicar o sujeito, e o laudo positivo nem sempre cumpra o efeito de beneficiá-lo. A discricionariedade conferida ao juiz parece ser utilizada sempre em malefício do réu.

Em casos em que se debateu a possibilidade do reconhecimento do princípio da insignificância, a questão da periculosidade pareceu vinculada à existência de antecedentes, ainda que por fatos pouco ou nada danosos. Por se tratar de uma questão de tipicidade e não de culpabilidade, o STJ entende que seria possível reconhecer, desde que presentes outros critérios. O entendimento majoritário atualmente a respeito do princípio é o de que, para o seu reconhecimento, deve o julgador sopesar: "a mínima ofensividade da conduta do agente, a nenhuma periculosidade social da ação, o reduzido grau de reprovabilidade do comportamento e a inexpressividade da lesão jurídica provocada". Enquanto em alguns julgados a mera existência de antecedentes já afasta o princípio, no HC 314.232 - RS, ao contrário, apesar dos antecedentes, reconhece a relatora a atipicidade da subtração de sete barras de chocolate, no valor de $\mathrm{R} \$ 16,10$, que posteriormente foram restituídas à vítima.

De acordo com o entendimento majoritário dessa Colenda Turma, cada fato deve ser analisado em seu contexto próprio, e tendo em vista as peculiaridades que cercam o ocorrido, entendo que a reincidência (três sentenças condenatórias pelo crime de furto às fls. 46-50) e vários inquéritos em andamento, não impedem o reconhecimento da insignificância. Isso porque, levar em conta outros fatos da vida do réu ou indiciado desborda a lógica da insignificância que, como visto, centra-se no fato em si e não na pessoa do delinquente. A tipicidade é material quando aquele determinado fato em apuração revela características tais que interessam, sim, ao Direito Penal e, pois, a sua persecução é fator de apaziguamento social. Daí porque, na espécie, pensar em sentido contrário, a meu ver, é dar, data venia, prioridade ao superado direito penal do autor, em detrimento do direito penal do fato (BRASIL, 2015a). 


\section{Democracia}

Em outro caso, porém, o direito penal de autor foi determinante na decisão do Tribunal. Após extensa explanação, inclusive doutrinária, entendeu não ser possível a incidência de tal princípio. Justificou essa tese apontando: “(...) dados significativos que revelam a acentuada ofensividade e reprovabilidade da conduta do paciente, a reclamar a atuação persecutória do Estado (...)" (BRASIL, 2014i).

O Superior Tribunal de Justiça apontou, ainda, que

(...) o princípio da insignificância decorre de política criminal e sua aplicação deve ser balizada pela análise conjugada também das particularidades de cada caso concreto, à luz dos postulados da fragmentariedade e da intervenção mínima do Estado em matéria penal. Embora a res furtiva - à época avaliada em $\mathrm{R} \$ 51,00$ (cinquenta e um reais) (fl. 46) - não goze, em princípio, de elevado valor econômico, o paciente, a despeito de sua inimputabilidade, é pessoa habituada a práticas delitivas (BRASIL, 2014i).

Desse modo, o STJ entendeu, assim como o Juízo de Primeiro Grau e o Tribunal de Justiça, que o paciente era "pessoa de alta periculosidade", pois possuía diversos procedimentos penais em instrução e já detinha mais de quatro condenações, devendo, por isso, ser submetido à medida de internação. Diante da reiteração da conduta - e não da periculosidade extraída da gravidade do fato - é que o STJ argumentou que não havia, no caso, a aplicação do princípio da insignificância penal (BRASIL, 2014i).

Outro elemento importante que aparece em algumas decisões é, diante da irresignação do Ministério Público com a transferência para o tratamento ambulatorial mesmo em casos de crimes apenados com reclusão, o entendimento de que, pelo menos na Sexta Turma, a medida de segurança vincula-se à periculosidade do agente e não à gravidade do delito. Assim, é facultada ao magistrado a escolha do tratamento mais adequado ao inimputável, em consonância com os princípios da adequação, razoabilidade e proporcionalidade (BRASIL, 2014g). Isso implica, necessariamente, a possibilidade de imposição de medida menos grave do que aquela prevista em lei.

Nos acórdãos que tratam sobre a periculosidade do agente, alguns não a discutem em razão da via eleita, por exemplo, os agravos regimentais ou mesmo o recurso especial. Nesses casos, são mencionados de maneira ampla os laudos presentes nos autos, bem como indicada a periculosidade a partir da gravidade do sofrimento mental ou dos crimes cometidos. Além disso, aparece com frequência a menção ao artigo 97 do Código Penal, que imporia a medida de internação em fatos delituosos punidos com reclusão (BRASIL, 2016a).

Nesse ponto encontra-se uma grande divergência entre as turmas do próprio STJ. Há uma dificuldade evidente na definição sobre a natureza da medida de segurança se considerada a ausência de culpabilidade e a impossibilidade de conferir tratamento mais gravoso àquele que é irresponsável pelos danos causados. Diante da complexidade dessa matéria, a Sexta Turma vem decidindo, com base tanto nos princípios constitucionais que consagram a dignidade da pessoa humana e os direitos da pessoa com sofrimento mental, quanto na opção política antimanicomial, de se optar pela liberdade sempre que possível. 
[...] na fixação da medida de segurança - por não se vincular à gravidade do delito perpetrado, mas à periculosidade do agente -, cabível ao magistrado a opção por tratamento mais apropriado ao inimputável, independentemente de o fato ser punível com reclusão ou detenção, em homenagem aos princípios da adequação, da razoabilidade e da proporcionalidade (BRASIL, 2016b).

Trata-se, conforme se verifica na decisão do HC n. 214.143/MG, de uma interpretação do artigo 97 do CP conforme a Constituição, situando a liberdade de ir e vir como um direito fundamental que prevalece em relação à legislação ordinária.

[...] o artigo 97 do Código Penal, ao disciplinar os critérios que, de um modo ou outro, afetam a liberdade ambulatorial do indivíduo, instituiu uma lógica abstrata e homogênea de rigidez que, no Estado Constitucional, não mais se admite, exatamente em razão daqueles princípios fundamentais que visam à, mediata ou imediatamente, resguardar a liberdade de ir e vir da pessoa (BRASIL, 2014i).

Sustenta o julgado que a liberdade é a regra e a exceção é a privação da liberdade, questão que deverá ser decidida caso a caso, levando em conta "[...] toda a carga de subjetividade presente na demanda penal, como a personalidade e a periculosidade do agente". Assim, a mera previsão do artigo 97 não vincula o juiz: a previsão legal da pena de reclusão ou de detenção não deve ser tomado como critério único, "porquanto estar-se-ia desvirtuando a sua finalidade - tanto em relação ao agente como ao bem comum - dada sua natureza preventiva e terapêutica" (BRASIL, 2014i).

No caso que estava sendo julgado, o Tribunal de origem havia mantido a internação em razão da folha de antecedentes criminais, que, por si sós, indicariam a periculosidade do agente, sem fazer qualquer menção a laudos periciais. O laudo que aparece é apenas aquele de sanidade mental, que não aponta nenhum critério de periculosidade (BRASIL, 2014i).

Assim, a flexibilização da interpretação do artigo 97 do Código Penal, bem como do estabelecimento adequado ao tratamento somente pode ocorrer se for para favorecer o indivíduo nessa condição, e não o contrário. Sendo assim, para a sexta turma, é admissível que em fatos cuja pena prevista é de reclusão, pode o juiz determinar a realização de tratamento ambulatorial. Não pode, porém, determinar, em caso de fato cuja pena é detenção, impor medida de internação.

Por outro lado, a Quinta Turma entende que o artigo 97 deve ser aplicado em sentido exatamente oposto: quando a pena é de reclusão, obrigatoriamente deve ser imposta medida de internação, facultada, porém, ao magistrado, a imposição de qualquer dos regimes em caso de a pena ser de detenção. É o que afirma o voto do relator no HC 313.907 - SP: "Esta Corte de Justiça firmou entendimento de que o tratamento ambulatorial é exceção, possível apenas nos casos de crimes punidos com detenção, desde que observadas as condições de periculosidade do agente, à luz do livre convencimento motivado do magistrado (BRASIL, 2015b). Da mesma forma, a relatora do HC 335.665/SP: "De fato, o texto legal somente atribuiu ao juiz a discricionariedade diante das supracitadas medidas no tocante aos crimes apenados com detenção. Nesses casos, cabível a averiguação da periculosidade do acusado para respaldar a adoção de uma medida ou de outra" (BRASIL, 2015c). 


\section{Humanos e \\ Democracia}

Essa divergência em decisões do mesmo Tribunal e no mesmo ano mostra a dificuldade da inserção de uma perspectiva desinstitucionalizadora e a prevalência de uma leitura positivista da lei, desconsiderando-se toda a principiologia constitucional, e também aquela derivada dos direitos específicos das pessoas com sofrimento mental. Por outro lado, percebe-se uma grande inconsistência, pois os mesmos magistrados que se posicionam no sentido de não permitir medida menos grave em caso de reclusão, ao final do cumprimento do tempo correspondente à pena em abstrato serão unânimes em libertar o sujeito de qualquer forma, independentemente de laudos ou mesmo das condições de reintegração social da pessoa. É o que se verá a seguir.

\subsection{A pena máxima em abstrato como parâmetro: superação ou manutenção do antigo paradigma segregador?}

Tanto no período anterior quanto no posterior à Súmula 527 do STJ, foram numerosos os julgados tratando sobre o tempo máximo de duração da medida de segurança. Como visto, o STJ já havia uniformizado sua jurisprudência no sentido de compreender o limite máximo como sendo o do máximo da pena em abstrato cominada ao delito. Assim, independentemente dos laudos psiquiátricos declarando ou não a cessação da periculosidade, ultrapassado esse prazo deve obrigatoriamente o paciente ser posto em liberdade.

Ocorre que, apesar de esse entendimento ser muito bem fundamentado na proibição da perpetuidade das penas (artigo 5으. XLVII, alínea $b$ da Constituição Federal), sabendo-se que a medida de segurança é um tipo de sanção, sobretudo aquela que traz a privação de liberdade, ele parece absolutamente incoerente com toda a principiologia ligada à medida de segurança, e mesmo às políticas antimanicomiais. Isso porque toda a luta antimanicomial de busca pela desinstitucionalização baseia-se na crítica à própria psiquiatrização da vida, e na possibilidade de tratamento real e alternativo aos problemas da institucionalização, a ser conferido a pessoas que sofrem de doenças mentais. Daí que como visto na maior parte das 80 decisões analisadas, os princípios da reforma psiquiátrica não estão de uma maneira geral informando os juízes, e o cuidado com o ser humano é o último a ser observado nesses processos. Trata-se, isso sim, de um tratamento que, como historicamente ocorreu, os tem como pessoas perigosas e que, portanto, devem ser afastadas da sociedade. Se, por um lado, é um grande avanço saber que o STJ finalmente reconheceu os abusos cometidos contra inimputáveis no sistema de Justiça brasileiro, por outro lado isso ocorre a partir de uma construção meramente jurídica, nunca baseada na política criminal, que deve ser condizente com a desmanicomialização durante toda a medida de segurança, e não somente quando o indivíduo completa anos de institucionalização, muitas vezes sem nenhuma atenção à sua saúde, e sem nenhuma preocupação com sua inserção social.

Além disso, mesmo do ponto de vista jurídico, há enormes contradições. Em vários casos em que o reconhecimento da inimputabilidade se dá posteriormente à sentença, já se sabe qual teria sido a pena em concreto aplicada pelo crime caso o agente fosse imputável. Assim sendo, para manter o princípio da isonomia, defendido pelo STJ (BRASIL, 2014h), de que o inimputável não pode sofrer uma resposta mais gravosa do que o imputável, o que deveria valer seria a pena em concreto, e não a pena em abstrato, contudo não foi o que ocorreu na maior parte dos casos analisados. No HC 251.296-SP, a relatora claramente repisou 
o argumento de que ao término do prazo correspondente ao tempo máximo cominado em abstrato ao delito praticado, ainda que não cessada a periculosidade do agente, "deve cessar a intervenção do Estado na esfera penal" (BRASIL, 2014h). No caso em apreço, entretanto, o STJ concluiu não ser possível constatar, a partir da documentação dos autos, que o paciente havia atingido o termo máximo em abstrato para cumprimento da medida, apesar de haver cumprido o prazo da pena em concreto determinado em sentença.

De fato, compulsando os autos, verifica-se que a medida de segurança imposta ao paciente foi extinta, não pelo cumprimento do máximo da pena cominada abstratamente ao delito, mas porque o tempo de privação de liberdade a ele imposto por internação (mais de 10 anos), superava a pena imposta ao sentenciado, substituída por medida de segurança (2 anos e 8 meses de reclusão) (fl. 45), razão pela qual descabida a extinção da medida de segurança, na espécie, enquanto não cessada a periculosidade do agente, merecendo reforma a decisão agravada (BRASIL, 2016c).

Assim, o mesmo indivíduo, se não tivesse sido declarado inimputável teria concretamente, comprovado pela sentença, cumprido tempo menor de reclusão do que o teve por ter sido declarado inimputável. Diferentemente dessa decisão, em outro caso, em que houve superveniência da inimputabilidade, a ordem de habeas corpus foi concedida pelo STJ: "Nos termos da jurisprudência desta Corte, em se tratando de medida de segurança aplicada em substituição à pena corporal [...] sua duração está adstrita ao tempo que resta para o cumprimento da pena privativa de liberdade estabelecida na sentença condenatória, sob pena de ofensa à coisa julgada" (BRASIL, 2016d). Ou seja, apesar de colidir com o caso anterior no que se refere ao princípio da isonomia, ele não é enfrentado pela decisão, sendo somente levada em consideração a ofensa à coisa julgada. Na prática, porém, ocorre que aquele que foi declarado inimputável desde o julgamento de primeira instância deve cumprir a pena em abstrato, enquanto que o que teve a declaração da inimputabilidade superveniente é beneficiado pela duração da pena em concreto. Nota-se, assim, outra vez a violação ao princípio da isonomia.

Se, por um lado, a Súmula representa um benefício ao inimputável com sofrimento psíquico por uniformizar um entendimento que é, há anos, controverso e que servirá como padrão aos juízes, por outro lado pode representar uma continuidade, que é assim percebido quando se considera as formas alternativas de tratamento que poderiam ser aplicadas, garantindo os direitos e possibilitando a reinserção social.

A insuficiência da Súmula diz respeito diretamente ao tratamento destinado ao inimputável, pois esse não sofrerá alterações. Isso posto, por mais que o tempo de internação esteja propenso a diminuir em virtude da Súmula, o tratamento fornecido seguirá os mesmos parâmetros estudados - que não são adaptados à Lei e, portanto, aos princípios antimanicomiais.

Desse modo, parece que por mais que as decisões sejam uniformizadas, de forma gradativa, quanto à limitação temporal para as medidas de segurança entre todos os órgãos julgadores, a questão da incorporação da Lei n. 10.216/2001 ainda deverá ser enfrentada, até que suas disposições sejam aplicadas ao âmbito do Direito Penal de maneira uniforme. 


\section{Democracia}

Humanos e

Para isso, porém, é necessária uma alteração da percepção social do inimputável, que proporcione o seu tratamento como sujeito de direitos não somente quando estão presentes evidentes violações da lei - casos em que as ordens de habeas corpus foram concedidas mas também quando essas violações são constituídas pela própria aplicação da lei - casos em que a periculosidade e os laudos psiquiátricos foram invocados para retirar direitos.

\section{CONCLUSÃO}

O processo de classificação de comportamento tem raízes culturais, religiosas e sociais. Por meio desse processo busca-se a exclusão dos indivíduos que não se adéquam à "normalidade" característica da maioria da população. A medida de segurança é a espécie de sanção penal que se destina à segregação social de pessoas com sofrimento mental que incorrem no cometimento de crimes.

Com a institucionalização desses indivíduos o grupo considerado "normal" parece estar livre e "purificado", enquanto isso, o Judiciário "cumpre" sua função de retribuir àqueles que cometeram atos ilícitos protegendo, ainda, a sociedade. Ademais, o elemento que diferencia a medida de segurança da pena é a sua finalidade de tratamento ao sujeito que se destina. Nesse viés, o advento da Lei n. 10.216, em 2001, representou o surgimento de avanços no campo da Psiquiatria, ao dispor sobre os direitos dos portadores de sofrimento mental e estabelecer diretrizes acerca do sistema de saúde mental.

Em contrapartida, e apesar de a lei não excluir de seu campo de aplicação as internações determinadas pelo Judiciário aos inimputáveis pelo sofrimento psíquico, dificilmente se visualiza a efetivação de suas normas nesses casos. A inserção dos princípios da lei no Direito Penal encontra barreiras físicas e sociais, tendo em vista a falta de estrutura para atender à demanda de instituições voltadas ao tratamento terapêutico, bem como o despreparo social para a instituição de métodos alternativos (e, portanto, terapêuticos) de tratamento.

Assim, ainda que a legislação federal tenha concretizado avanços e dispensado atenção aos portadores de sofrimento mental, não se pode afirmar que esse avanço tenha provocado efeitos na esfera penal. Essa constatação é possível ante a análise jurisprudencial realizada, na qual pôde ser visualizada a dificuldade de inserção, pelos órgãos do Judiciário, dos elementos constantes na Lei 10.216/2001 nas decisões. Se, por um lado, alguns dos julgados mencionaram a referida Lei, por outro lado isso somente ocorreu quando estavam presentes violações evidentes da própria lei penal ou a jurisprudência consolidada do STJ, como na prisão de inimputáveis em presídios comuns ou no excesso de prazo no cumprimento da medida. Em casos nos quais se invocou o princípio da isonomia para garantir o reconhecimento do princípio da insignificância, o cumprimento da pena em concreto, ou a possibilidade de tratamento ambulatorial em casos de condutas apenadas com reclusão, jamais houve menção à Lei $10.216 / 2001$. Pelo contrário, sobrepõe-se o tradicional discurso positivista da periculosidade, derivada mais dos fatos passados do que de qualquer possibilidade de prognose, até porque em muitos casos não sustentada sequer em laudos psiquiátricos.

Nota-se, assim, que, pelo menos no âmbito do STJ, em que não está em discussão uma dilação probatória, mas sim casos de violação do direito de ir e vir e controvérsias jurisprudenciais, a influência do poder psiquiátrico aparece de forma secundária, somente quando o julgador realmente precisa de uma justificação mais robusta para uma decisão anteriormente 
tomada. A dificuldade de real inovação no que tange à garantia dos direitos não aparece nas decisões analisadas, de modo que os ideais de desinstitucionalização propostos pela Lei de reforma psiquiátrica e as adaptações às formas de tratamento humanitárias não atingiram os hospitais de custódia e tratamento psiquiátrico destinados à internação via medida de segurança.

Se, por um lado, observa-se na atualidade um reconhecimento dos direitos das pessoas com sofrimento mental, e das pessoas imputáveis que cometeram crimes, por outro lado, às pessoas com sofrimento mental e que praticaram atos previstos como crimes não resta qualquer reconhecimento. Este é o local reservado aos loucos no Direito Penal brasileiro: o do arbítrio.

\section{REFERÊNCIAS}

BARATTA, A. Criminologia crítica e crítica do direito penal. 3. ed. Rio de Janeiro: Revan; ICC, 2002.

BATISTA, N. Cem anos de reprovação. In: NASCIMENTO, A.; BATISTA, N. (org.). Cem anos de reprovação: uma contribuição transdisciplinar para a crise da culpabilidade. Rio de Janeiro: Revan, 2011. p. 161-180.

BIRMAN, J. Genealogia da reprovação: sobre a periculosidade, a normalização e a responsabilidade na cena penal. In: NASCIMENTO, A.; BATISTA, N. (org.). Cem anos de reprovação: uma contribuição transdisciplinar para a crise da culpabilidade. Rio de Janeiro: Revan, 2011.

BRASIL. Código Penal. 13. ed. Porto Alegre: Verbo Jurídico, 2012.

BRASIL. Constituição da República Federativa do Brasil. Brasília, DF: Senado Federal, 1988.

BRASIL. Lei 10.216, de 6 de abril de 2001. Dispõe sobre a proteção e os direitos das pessoas portadoras de transtornos mentais e redireciona o modelo assistencial em saúde mental. Publicada no Diário Oficial da União em 9 de abril de 2001. Disponível em: http://www.planalto.gov.br/ccivil_03/leis/leis_2001/l10216.htm. Acesso em: 2 abr. 2015.

BRASIL. Código Criminal do Imperio do Brazil. 16 de dezembro de 1830. Disponível em: http://www.planalto.gov. br/ccivil_03/leis/lim/lim-16-12-1830.htm. Acesso em: 23 ago. 2012.

BRASIL. Decreto n. 847 de 11 de outubro de 1890. Promulga o Codigo Penal. Disponível em: http://www.planalto.gov.br/ccivil_03/decreto/1910-1929/D17943Aimpressao.htm. Acesso em: 24 ago. 2012.

BRASÍLIA. Lei no 7.210, de 11 de julho de 1984. Institui a Lei de Execução Penal. Brasília, 1984. Disponível em: http://www.planalto.gov.br/ccivil_03/LEIS/L7210.htm. Acesso em: 14 jul. 2015.

BUSTOS RAMÍREZ, J. J.; HORMAZÁBAL MALARÉE, H. Lecciones de derecho penal. Madrid: Trotta, 1999. V. II.

CARVALHO, S.; WEIGERT, M. A. B. A punição do sofrimento psíquico no Brasil: Reflexões sobre os impactos da Reforma Psiquiátrica no Sistema de Responsabilização Penal. Revista de Estudos Criminais, n. 48, p. 55-90, jan./ mar. 2013.

CARVALHO, S. Pena e medidas de segurança no direito penal brasileiro. São Paulo: Saraiva, 2013.

FOUCAULT, M. História da loucura na Idade clássica. 8. ed. São Paulo: Perspectiva, 2005.

FOUCAULT, M. A evolução da noção de "indivíduo perigoso" na psiquiatria legal do século XIX. In: MOTTA, Manoel Barros da (org.). Ditos e escritos. Ética, sexualidade, política. Rio de Janeiro: Forense Universitária, 2004. p. 1-25. V. 5.

FOUCAULT, M. Os anormais: curso no Collège de France (1974-1975). 2. ed. São Paulo: Martins Fontes, 2010.

FOUCAULT, M. Vigiar e punir: nascimento da prisão. Tradução Raquel Ramalhete. 37. ed. Petrópolis: Vozes, 2009. FRANK, R. Sobre la estructura del concepto de culpabilidad. Montevideo, Buenos Aires: BdeF, 2002.

MATTOS, V. Uma saída: preliminares para a desconstrução das medidas de segurança. Rio de Janeiro: Revan, 2006.

NUCCI, G. S. Código Penal Comentado. 11. ed. São Paulo: Revista dos Tribunais, 2012.

PAVARINI, M.; GIAMBERARDINO, A. Teoria da pena e execução penal: uma introdução crítica. 2. ed. Rio de Janeiro: Lumen Juris, 2012.

QUEIROZ, P. Curso de Direito Penal. 10. ed. Parte geral. Bahia: JusPodivm, 2014. V. 1.

ROXIN, C. La teoría del delito en la discusión actual. Traducción Manuel Abanto Vásquez. Lima: Grijley, 2007.

SANTOS, J. C. dos. Direito Penal: Parte geral. 3. ed. Curitiba: ICPC; Lumen Juris, 2008. 


\section{Humanos e \\ Democracia}

TAVARES, J. Culpabilidade e individualização da pena. In: NASCIMENTO, André; BATISTA, Nilo (org.). Cem anos de reprovação: uma contribuição transdisciplinar para a crise da culpabilidade. Rio de Janeiro: Revan, 2011. p. 121-152.

ZAFFARONI, E. R.; PIERANGELI, J. H. Manual de direito penal brasileiro. 7. ed. São Paulo: Revista dos Tribunais, 2008. V. 1.

ZAFFARONI, E. R.; BATISTA, N.; ALAGIA, A.; SLOKAR, A. Direito Penal Brasileiro. Rio de Janeiro: Revan, 2010. V. II.I.

\section{REFERÊNCIAS DO CORPUS DE PESQUISA}

BRASIL. Superior Tribunal de Justiça. Habeas Corpus no 284011. São Paulo. Relator: Min. Felix Fischer. Acórdão de 16 de setembro de 2014. 2014a.

BRASIL. Superior Tribunal de Justiça. Habeas Corpus no 300654. São Paulo. Relator: Min. Ericson Maranho. Acórdão de 9 de dezembro de 2014. 2014b.

BRASIL. Superior Tribunal de Justiça. Habeas Corpus no 303863. São Paulo. Relator: Min. Felix Fischer. Acórdão de 18 de novembro de 2014. 2014c.

BRASIL. Superior Tribunal de Justiça. Habeas Corpus no 283049. São Paulo. Relator: Min. Marco Aurélio Bellizze. Acórdão de 24 de abril de 2014. 2014d.

BRASIL. Superior Tribunal de Justiça. Habeas Corpus no 284520. São Paulo. Relator: Min. Rogério Schietti Cruz. Acórdão de 3 de abril de 2014. 2014e.

BRASIL. Superior Tribunal de Justiça. Habeas Corpus no 241246. São Paulo. Relator: Min. Moura Ribeiro. Acórdão de 25 de fevereiro de 2014. 2014f.

BRASIL. Superior Tribunal de Justiça. Agravo Regimental no Recurso Especial no 832848. Acre. Relator: Min. Nefi Cordeiro. Acórdão de 2 de dezembro de 2014. 2014g.

BRASIL. Superior Tribunal de Justiça. Habeas Corpus no 251296. São Paulo. Relatora: Min. Maria Thereza de Assis Moura. Acórdão de 25 de março de 2014. 2014h.

BRASIL. Superior Tribunal de Justiça. Habeas Corpus no 214143. Minas Gerais. Relator: Min. Rogério Schietti Cruz. Acórdão de 02 de setembro de 2014. 2014i.

BRASIL. Superior Tribunal de Justiça. Habeas Corpus no 314232. Rio Grande do Sul. Relatora: Min. Maria Thereza de Assis Moura. Acórdão de 24 de março de 2015. 2015a.

BRASIL. Superior Tribunal de Justiça. Habeas Corpus no 313907. São Paulo. Relator: Min. Gurgel de Faria. Acórdão de 28 de abril de 2015. 2015b.

BRASIL. Superior Tribunal de Justiça. Habeas Corpus no 335665. São Paulo. Relatora: Min. Maria Thereza de Assis Moura. Acórdão de 20 de outubro de 2015. 2015c.

BRASIL. Superior Tribunal de Justiça. Súmula no 527. O tempo de duração da medida de segurança não deve ultrapassar o limite máximo da pena abstratamente cominada ao delito praticado. Brasil, $2015 \mathrm{~d}$.

BRASIL. Superior Tribunal de Justiça. AgRg no Agravo em Recurso Especial no 875.985. Mato Grosso do Sul. Relator: Min. Jorge Mussi. Acórdão de 28 de junho de 2016. 2016a.

BRASIL. Superior Tribunal de Justiça. Habeas Corpus no 230842. São Paulo. Relator: Min. Sebastião Reis Júnior. Acórdão de 14 de junho de 2016. 2016b.

BRASIL. Superior Tribunal de Justiça. AgRg no Habeas Corpus no 336.452. São Paulo. Relator: Min. Nefi Cordeiro. Acórdão de 10 de novembro de 2016. 2016c.

BRASIL. Superior Tribunal de Justiça. Habeas Corpus no 373405. São Paulo. Relatora: Min. Maria Thereza de Assis Moura. Acórdão de 6 de outubro de 2016. 2016d. 